\title{
Case Studies on Sustainability Factors for Industrialised Building System (IBS)
}

\author{
Riduan Yunus $^{1 *}$, Rabitah Handan ${ }^{2}$, Salman Riazi Mehdi Riazi ${ }^{3}$ \\ ${ }^{1}$ Faculty of Civil \& Environmental Engineering, Universiti Tun Hussein Onn Malaysia, \\ 86400 Parit Raja, Batu Pahat, Johor, MALAYSIA
}

${ }^{2}$ Faculty of Engineering and Life Sciences, Universiti Selangor, 45600 Bestari Jaya, Selangor, MALAYSIA

${ }^{3}$ School of Housing, Building \& Planning, Universiti Sains Malaysia, 11800 Pulau Pinang, MALAYSIA

*Corresponding Author

DOI: https://doi.org/10.30880/ijscet.2020.11.02.007

Received 30 July 2020; Accepted 30 August 2020; Available online 02 September 2020

\begin{abstract}
This paper presents the outcomes of a case study to test the ability of the Guidelines for Sustainable Construction of Industrialized Building System (GSCIBS). An assessment on the implementation of IBS related guidelines in real projects contributes towards the improvement of these guidelines and ensure the significance of the decision tools in promoting sustainability. In addition, the process involved when using the GSCIBS also demonstrated how the guidelines can be used to assist designers when making a selection with regard to sustainability. Three case projects were selected based on their characteristics (location, accessibility of information, building construction, IBS project with high impact to community and high percentage IBS Score). The projects were categorized as non-residential buildings. Semi-structured interviews and documents' review were conducted to gather information from the respondents. In total, there are eleven (11) respondents who participated in the case study analysis. The confirmation by the industry participants shows that the guidelines are applicable and suitable to be used in Malaysia. The literal replication was achieved and provides strong evidence that the number of case studies is appropriate. The participants' comments and suggestions were taken into account in synthesising the project outputs. As a result, the GSCIBS are significant in improving sustainable deliverables of IBS application.
\end{abstract}

Keywords: Construction, guidelines, multiple projects, prefabrication, validation

\section{Introduction}

Construction industry plays an important role in the economy and has a significant impact to a nation's development. However, this industry also creates environmental problems due to its nature, which involving a huge amount of natural resources. In a building construction, conventional on site methods have long been criticized for their high risk to human health and safety. According to Jaillon \& Poon (2008), the application of conventional methods are labour intensive and cause significant damage to the environment. As a developing country, Malaysia is also facing these problems together with a shortage of construction labour as the main issue. Statistics show that $69 \%$ of the 
800,000 registered workers are foreign (Construction Industry Development Board Malaysia, 2008). These foreign workers are come from Indonesia, Bangladesh, Pakistan and Vietnam. Majorities of these foreign workers are unskilled and normally involved in the activities that require labour intensive. They can only operate manual tools such as conventional hammer, shovel and poker vibrator in completing the assigned job. If the employer needs them to operate more complex machines such as crane, excavator or concrete pump machine, they need to be sent to a training centre which requires additional cost. The reliability on migrant worker in Malaysia was low due to the factor that most of the migrant workers did not possess relevant skill demanded by the employer (Rahim Abdul Hamid et. al., 2018) In addition, previous research also confirmed that the dependency on unskilled foreign workers promotes economic and social problems (Abdul Kadir et. al., 2006).

This study is a continuity of the previous findings that have been reported in Yunus (2012) and Yunus (2014). The first publication identified critical factors in developing guidelines for sustainable construction of Industrialised Building System (IBS) (Yunus, 2012). There are 18 sustainability factors have been identified including: "construction time", "production", "waste generation", "constructability", "knowledge and skills", "defect and damages", "labour cost", “waste disposal”, “procurement system", “durability”, “working condition", "standardisation", “usage efficiency", "labour availability", "material consumption", "legislation", "project control guidelines" and "maintenance and operation costs". The identification of the factors was conducted by quantitative approach. Five categories were used to separate the critical factors into: ecological performance; economic value; social equity and culture; technical quality; and implementation and enforcement.

These critical sustainability factors are then further explored through semi-structured interviews. SWOT (strengths, weaknesses, opportunities, and threats) analysis is used to summarize findings from the interviews. The adoption of interviews provides opportunities for authors to investigate each factor in depth and formulate strategies to improve sustainability in IBS construction. An example of the outcomes is presented in second publication ((Yunus, 2012). An informative table is developed to provide guidelines for each critical factors. The table is helping designers to make a better decision to select to best strategies or action plans to improve sustainability.

This paper presents on the findings of the case studies conducted. This process able to demonstrate how the GSCIBS may assist designers to improve sustainability. It is tested in the real projects. Cases needed to be carefully selected so that they sufficiently represent the current IBS development in Malaysia. The number of cases is sufficient when all the cases turn out as predicted. The replication provides strong evidence that the study framework and developed guidelines improve the sustainable deliverables for IBS applications. In this research, three projects were identified as having the potential to validate and verify the findings in the questionnaire survey and semi-structured interviews.

\section{Selection of Case Study Projects}

The criteria for the selection of the case studies were based on their IBS score results and their characteristics in relation to promoting sustainability. According to Flyvbjerg (2006), the case study selection must focus on the research problems and must be able to provide rich information to answer the research questions. This means the selected projects must be able to provide sufficient data in formulating the solutions. The following criteria were used in selecting the appropriate case study projects:

\footnotetext{
i. The site and location of the projects were in Malaysia

ii. Information about the case study projects was accessible and participants were willing to cooperate

iii. The main activities in the case project focussed on building construction and did not focus on infrastructure development or other construction facilities (e.g. dam, communication tower)

iv. The case project was an IBS project with the potential for high impact on a local community and the environment

v. As evaluated by the IBS score, there was a high percentage of IBS component usage in the project
}

In Malaysia, the implementation of sustainability is still in its infancy and the concept has not been widely applied in construction projects (Abidin, 2010). With support from the government, many researches have been conducted to improve construction project delivery Yunus, 2012; Abd Hamid \& Mohamad Kamar, 2011; Masrom et.al., 2015). Construction projects are assumed to be able to improve sustainability when the building project is evaluated at more than $70 \%$ on the IBS score. However, the objective of the project in pursuing sustainability is typically not clear. The people involved at the project level struggle to integrate sustainability as there are no guidelines or organised procedures.

On the other hand, the level of awareness about the importance of sustainability is increasing over time. With support from the government and extensive research on this matter, it is believed that the scenario could change and project deliverables could be improved. Advanced technology and innovation in construction, such as IBS applications, could deliver more sustainable construction compared to conventional construction. 
The project types all relate to the construction industry and use IBS applications in their structural elements. These projects were located in different regions in Malaysia, namely, Penang, Melaka and Johor. The building function in each project is different and this provides interesting comparisons. These characteristics make the investigation more meaningful, as they are representations of the suitability and applicability of the developed frameworks and guidelines for any type of IBS project. Considering these criteria, three case study projects which fully satisfied all the predetermined requirements were selected. Table 1 shows the characteristics of each case study project.

Table 1 - Characteristics of case study projects

\begin{tabular}{|c|c|c|c|}
\hline \multirow[b]{2}{*}{ Project Criteria } & \multicolumn{3}{|c|}{ Characteristics } \\
\hline & Case Project A & Case Project B & Case Project C \\
\hline Location & Penang & Melaka & Johor \\
\hline $\begin{array}{l}\text { Building } \\
\text { Characteristics }\end{array}$ & Halls and office buildings & Office building and storage area & $\begin{array}{l}\text { Educational building } \\
\text { and its facilities }\end{array}$ \\
\hline Project & $\begin{array}{l}\text { To provide a centralised } \\
\text { administration office and trial } \\
\text { hall for solving legal problems } \\
\text { and supporting justice } \\
\text { processes }\end{array}$ & $\begin{array}{l}\text { To provide a centralised office for } \\
\text { administration with a storage } \\
\text { space for managing the tax } \\
\text { activities and supporting the } \\
\text { government policies }\end{array}$ & $\begin{array}{l}\text { To provide facilities } \\
\text { and expand access to } \\
\text { the local community } \\
\text { with a high-quality } \\
\text { education }\end{array}$ \\
\hline
\end{tabular}

\section{Case Study Data Collection}

The case studies were conducted for about two months to ensure the developed guidelines were ready before the case studies could be executed. As mentioned earlier, the main objective of this methodology is to validate the guidelines and to confirm the process involved in assisting the decision-making. Accordingly, two main collection methods were used in the case study: interviews, and archival records and documents.

\subsection{Interviews}

The interviews were conducted to gain insights from the experiences of professionals involved in the projects and to validate the suitability or potential of the developed guidelines for improving sustainability in IBS applications. These professionals were the key players and the decision-makers in the projects, including Project Managers, Designers, Construction Managers, and Authority Officers. Table 2 shows the list of the 11 interviewees who participated in the case studies.

The participation of people in different positions and organisations in the same project gave the researcher the opportunity to synthesis, validate and verify the findings. The expert views in order to complete their role in the construction projects are providing an insight on how the operation of construction industry can be improved. All respondents supported the objective of this research and believed that the proposed guidelines were able to improve sustainability in IBS construction.

Table 2 - Interviewee profiles

\begin{tabular}{ccccc}
\hline Case Project & Interviewee ID & Position & Location & Duration \\
\hline & 1A & Senior Design Engineer & Kuala Lumpur & 1 hour \\
2A & Project Manager & Penang & 1.5 hours \\
& 3A & Architect & Kuala Lumpur & 1 hour \\
& 1B & Project Engineer & Melaka & 1 hour \\
& 2B & Project Manager & Melaka & 1 hour \\
& 3B & Design Engineer & Kuala Lumpur & 1.5 hours \\
B & 4B & Executive Director & Melaka & 1 hour \\
& 1C & Project Manager & Johor & 1.5 hours \\
& 2C & Assistant Project Manager & Johor & 1 hour \\
& 3C & Architect & Johor & 1.5 hours \\
& 4C & Structural Engineer & Johor & 1 hour \\
\hline
\end{tabular}




\subsection{Archival Records and Documents}

When invited to participate in the interview sessions, the respondents were requested to provide related documents for the project such as IBS score report, progress report, drawing and specifications, environmental impact assessment report, and awards and achievements related to the project. These project records and documents provided additional information and facts to be synthesised by the researcher. The written documents and archival records also used as a verification tool to check the reliability of the information gathered from the interview session.

\section{Findings}

The findings from all case projects are discussed in this section. The project background and additional information related to the projects are also presented in this section. In summary, all the three case studies confirmed that the GSCIBS able to improve sustainable deliverables in IBS implementation. The projects were categorized as non-residential buildings. The guidelines provide a structured and simple assessment tool in ensuring the critical sustainability factors are taken into account. Better decision making can be achieved by referring to GSCIBS. The application of GSCIBS is suitable for both, government and private projects. Next section will explain in detail on each project selected.

\subsection{Project A}

Project A was a building project that provided a diverse range of facilities for Sharia justice hearings which cost about RM33 million. The seven-storey complex included five Sharia high courts, one lower Sharia court, a police station, defendant cells and a cafeteria. The construction land belonged to the state government and there were two existing bungalows on the proposed construction site. One was used by the National Anti-Drugs Agency as a meeting point and the other one was used as a garage for state government vehicles. The construction of this project replaced these building and aimed to provide more benefits to the local community. As explained by the respondent in the interview session, this project was the first court construction in Malaysia to use the IBS application.

Three respondents related to this project were interviewed. Each respondent represented a different organisation, namely, the civil and structural design firm, architecture firm and contractor company. All respondents confirmed that the framework provided them the ability to improve the sustainable deliverables of IBS applications and agreed that the 18 critical sustainability factors were significant.

The proposed guidelines were assessed by the respondents and generally they believed that sustainability could be improved when the IBS buildings were designed with the assistance of the proposed guidelines. Since there were previously no assessment tools or decision support tools for sustainability during the design stage, the structural designer (Respondent 1A) highlighted that most of the problems stated in the guidelines were experienced in this project especially problems involving the institutional dimension.

In regard to the legislation factor, the respondent $1 \mathrm{~A}$ stated that the organisational review was not conducted in this project. Problems arise when every stakeholder joins a "circle of blame" whereby no-one wants to be responsible for any sustainability efforts. This echoes the findings from previous literature showing that project participants often criticised each other for the lack of sustainable initiatives and implementation (Abd Hamid \& Mohamad, 2011; Lutzkendorf \& Habil 2011; Yang, 2012). Abidin (2010) argued that as long as there is no by-law or regulation enforcing the existing legislation to improve sustainability, the construction players will not care. Respondent 3A claimed that most of the time, the architect needed to emphasise the importance of sustainability in this project; yet, cooperation and responsibility for steering sustainability should exist among all the key stakeholders.

Delivering sustainable construction requires action from all those engaged in the design, construction and maintenance activities for IBS applications. Proper planning and early integration can create consensus starting from the design stage which avoids miscommunication and misleading. The sustainable objectives should be set in the earlier stage so that the IBS project is always on track. Over time, the monitoring process should take place. Therefore, it was advised by Respondent $3 \mathrm{~A}$ that the guidelines should include a recommendation that a sustainability committee is set up and led by the sustainability manager. However, in Project A, the committee was not able to be set up since the levels of knowledge and experience among the players on sustainability were low and required more in-depth understanding of the sustainability concept and its applicability. The participants in this case study project confirmed that the recommendations provided in relation to the 'knowledge and skills' factor would be able to overcome this problem.

The in-house designer and manufacturer allowed the contractor to proceed with the construction works even though the details drawing for the whole construction is not complete. However, the drawings needed to be approved before the permission was given by the local authority to allow the construction to start. This is one of the good examples of the assistance provided in the proposed guidelines where the procurement system adopts concurrent engineering and an effective scheduling system.

The project control guidelines were highlighted by Respondent 1A as an opportunity to keep the management and project teams informed and up-to-date on the sustainability efforts and the impact on the construction activities. The respondent suggested that the recommendation should also include an interim report which identifies existing 
unsustainable practices and the organisation's response in integrating sustainability. Moreover, incentives and appreciation based on the performance would motivate the project participants to actively pursue sustainability. In conclusion, it was agreed by the respondents that the guidelines helped the players at the project level to practise the sustainability concept.

\subsection{Project B}

Project B was a building project that provided workstations and storage facilities for a government agency, The Royal Malaysian Customs. This agency is responsible for administering tax policies, indirectly helping the government to collect revenue and is also a critical facilitator in the global trade system.

The construction site was located in Melaka, which is about $145 \mathrm{~km}$ from the south of the capital, Kuala Lumpur. The building construction consisted of a three story building, a guard post and a refuse centre. The project was relatively small with a contract price of RM8.8 million. The structure of the building mainly used precast concrete such as for piles, slabs, columns and walls. The total IBS score was $70 \%$.

Four respondents from this project were interviewed. They represented different organisations and have vast experience in the construction industry. Respondent $1 \mathrm{~B}$ represented the client and was responsible for monitoring the construction process and ensuring the project was able to be completed. In the interview session, Respondent $1 \mathrm{~B}$ highlighted that there was a problem during the production of the IBS components. This was mainly because of the local authority fragmentation. In this project, the authority for the mechanical and electrical systems failed to get agreement with the structural engineer. There were some discrepancies regarding the location of wiring and ducting installation. This resulted in delays and miscommunication among nominated sub-contractors. The recommendation provided in the guidelines to appoint a coordinator and assign skilled workers was seen as one of the solutions that could minimise fragmentation risk and help to eliminate this problem. The coordinator will be able to check any discrepancies in advance and the use of advanced technology such as pre-installed electric conduit and air conditioning systems will also reduce discrepancies. However, proper handling and effective planning are vital.

Even though the creativity in design for IBS constructions is sometimes limited, respondent $2 \mathrm{~B}$ emphasised that repetition and standardisation is important in IBS applications to ensure load stability especially when involving structural components. The standardisation of component size can reduce construction waste and, with the right combination, the aesthetic value of the IBS building will be better and more creative. In addition, an effective waste management will benefit the organization in term of cost saving by reducing the amount of waste that need to be sent to the landfill (Kasyar et. al., 2017). According to Luther and Bauer (1987), the adoption of precast concrete in their case study project permitted the designer to use smaller columns compared to the conventional method and provided more floor spaces compared to conventional construction. By reducing the size of the precast component, the dead load that needs to be supported by the structural frame system will be reduced. In Project B, the storage area was located on the ground floor. By not locating storage area on the upper floor, the dead load for slab can be reduced. The design standard recommends a higher safety factor should be provided for a storage area compare to the normal office area. With the usage of the precast column and beam, the length of span can be extended and can provide a larger area to accommodate storage requirements.

The distance and location of the prefabrication plant is important for selecting the best option, not only to reduce costs, but also to improve sustainability. The frequencies of the transportation need to be reduced and optimised to prevent traffic congestion and excessive usage of fossil fuel. Proper planning and systematic IBS component production are vital to eliminate unnecessary resource wastages. Respondents 3B and 4B highlighted that the Just-inTime (JIT) method proposed in the guidelines were able to speed up the construction process and eliminate doublehandling for IBS components and construction materials. Polat et. al (2006) stated that JIT in small batches of IBS components can reduce the inventory costs. For this project, only a small area required to storage building materials. Proper schedule was prepared to ensure that the IBS components only sent to the construction site when it is supposed to be installed in the building. The continuity of each activity will be carefully examined to prevent idling and pending for any successor activities.

In conclusion, the interviewees in this project confirmed that imbedding sustainability into the IBS application is crucial and the assistance provided in the developed guidelines was helpful in making decisions. The critical factors were confirmed as the most important impetus that encourages the practitioners to make it a priority in their decisionmaking to pursue sustainability.

\subsection{Project C}

Project $\mathrm{C}$ was located in Batu Pahat, Johor, which is an important district in Johor, the southern state in the peninsular of Malaysia. The construction project consisted of three blocks of classrooms, an administrative staff office, two blocks of laboratories, a canteen and five blocks of school support facilities. The total contract amount was RM32.7 million. According to the IBS score report, the percentage of IBS usage for this project was $72.79 \%$. This project was expected to be able to accommodate about 1200 students with its 30 classrooms. Pre-stress cable was used 
for the precast elements to distribute the structural load. The precast concrete was used as columns, beams, slabs and wall construction. For a procurement system, open tender was used to select contractors and participants in this project.

Four respondents from this project were interviewed to verify and validate the developed guidelines. The respondents agreed that the framework was able to improve sustainability in IBS applications. All the 18 factors were identified by the respondents as important factors to improve sustainability. Each critical factor, SWOT analysis and recommendation was discussed with each respondent during the interview sessions.

Respondent 1C highlighted the importance of waste management. As the project manager, he observed that waste management was neglected by his organisation. He also overlooked this part as the project manager in managing the construction waste due to placing a priority on the physical progress of the project. The respondent agreed that the developed guidelines provided assistance by reminding him of the importance of sustainability and identifying actions that need to be taken to improve sustainability in IBS. For example, he said he would provide different bins to separate the different types of waste for the next IBS projects.

As the designers, Respondents $3 \mathrm{C}$ and $4 \mathrm{C}$ highlighted that the guidelines were able to incorporate sustainability requirements by different stakeholders in the early stage. The simple and clear process provided in the guidelines would help the designers focus on the critical issues in making a selection or decision. The holistic consideration would allow them to take account of other key stakeholders' concerns on sustainability.

Respondent $2 \mathrm{C}$ stated that one of the greatest advantages of promoting sustainability in IBS applications is reducing the physical activities on the construction site and transferring those activities to the factory environment. However, skilled labour is still required on site and in the factory, and the availability of this skilled labour remained the most critical concern in his opinion. The recommendation in the guidelines to provide certification and training programs to local workers would help overcome the labour shortage in this field. Cooperation from technical institutions in providing sufficient training to local workers is vital. On the other hand, the IBS production plant should also be placed in strategic locations to minimise fossil fuel consumption and encourage the development of local economies.

Respondent 3C stated that the advanced technology and innovative techniques adopted in IBS application are able to improve building quality and durability. The perfect curing process, load testing assurances and use of factoryengineered concrete are some of the examples of innovation adopted in the construction of IBS buildings. These new methods replace the old conventions of building techniques which employed construction on site and often produced low quality buildings and required a lot of waiting time (for wet concrete to achieve its strength before dismantling the formwork). The controlled environment also reduces problems that occurred due to inconsistence temperature and monsoon season. The local construction industry needs to undergo a marked evolution in its development and maturity to catch up to the higher demand of present construction development (Razak et. al., 2010).

It can be concluded that the GSCIBS is helping the designer's team to consider on the significant factors for IBS application in improving sustainability. All the selected projects show a consensus on the potential of the GSCIBS to promote sustainable construction.

\section{Conclusion}

In this study, data collected from a questionnaire survey was further analysed by using semi-structured interviews. Then, the results obtained were presented in a systematic and structured guideline which called as GSCIBS. A case study enables the applicability and suitability of the GSCIBS to be investigated in-depth and to review whether any issues are being overlooked. The holistic and meaningful characteristics of real events could be achieved by a case study and it is directly increases the reliability of the research. The findings from this study shows that there is a room for improvement for the developed guidelines and importantly illustrate that the guidelines are practical to be used in order to improve sustainability for Industrialised Building System. Minor improvement was made based on the received comments. The GSCIBS help the decision-makers maximise the opportunities by using available strengths, avoid weaknesses, and diagnose possible threats in the examined issues. The recommendations formed an integrated action plan to present information on what and how to improve sustainability through tackling each critical factor during IBS development. It can be used as part of the project briefing documents for IBS designers. Most importantly, the case study shows that the guidelines provides a balanced view for designers to better understand sustainable potential for selected IBS components and prioritize attentions to manage sustainability issues. Due to several types of construction that have been set by the Construction Industry Development Board (CIDB), this study can be expanded to other categories; including social amenities, residential and infrastructure projects.

\section{Acknowledgement}

The authors would like to thank Universiti of Tun Hussein Onn, Malaysia and the Ministry of Higher Education, Malaysia (FRGS vot. 1578) for their generous sponsorship of this research. 


\section{References}

Abd Hamid, Z., and Mohamad Kamar, K. A. (2011). Editorial: Aspects of off-site manufacturing application towards sustainable construction in Malaysia. Construction Innovation: Information, Process, Management, 12, 4-10

Abdul Kadir, M. R., Lee, W. P., Jaafar, M. S., Sapuan, S. M., \& Ali, A. A. A. (2006). Construction performance comparison between conventional and Industrialised Building Systems in Malaysia. Structural Survey, 24(5), 412

Abidin, N. Z. (2010). Sustainable construction in Malaysia. Int. J. of Social Science, 5, 122-129

Construction Industry Development Board Malaysia. (2008). Malaysian Construction Outlook 2008. Kuala Lumpur: Construction Industry Development Board (CIDB) Malaysia

Flyvbjerg, B. (2006). Five misunderstandings about case-study research. Qualitative Inquiry, 12, 219-245

Jaillon, L., \& Poon, C. S. (2008). Sustainable construction aspects of using prefabrication in dense urban environment: a Hong Kong case study. Construction Management and Economics, 26(9), 953 - 966

Kasvar, K. K., Nagapan, S., Abdullah, A. H., Ullah, K., Deraman, R., Yunus, R., and Sohu, S. (2017). Cost Implication Analysis of Concrete and Masonry Waste in Construction Project. Pertanika Journal of Science \& Technology, 25, 177184

Luther, M. D., and Bauer, K. C. (1987). Using high-strength concrete simplifies precast column design. Concrete Construction, 32, 546-547

Lutzkendorf, T., and Habil, D. (2011). How to break the vicious circle of blame? The contribution of different stakeholders to a more sustainable built environment. PRAC Electronic Journal on Research for Architectural, Design and Construction, 1, 66-81

Masrom, M.A.N., Rahim, M.H.I.A, Mohamed, S., Chen, G.K., and Yunus, R. (2015). Successful criteria for large infrastructure projects in Malaysia. Procedia Engineering. 125, 143-149

Polat, G., Arditi, D., Ballard, G., and Mungen, U. (2006). Economics of on-site vs. off-site fabrication of rebar. Construction Management and Economics, 24, 1185-1198

Rahim Abdul Hamid, A., Inayah Mohd Khazid, N., Yunus, R., Halim, H.A. \& Raihan Abdul Razak, A. (2018). The emerging of employment gap in the Malaysian construction industry, International PostGraduate Conference on Applied Science and Physics 2017 (GRASP 2017), Journal of Physics: Conference Series. 1049 (1), Article number 012033

Razak I. A., Roy, M. H., Ahmed, Z., and Imtiaz, G. (2010). An investigation of the status of the Malaysian construction industry. Benchmarking: An International Journal, 17, 294 - 308

Yang, J. (2012). Editorial: Promoting integrated development for smart and sustainable built environment. Smart and Sustainable Built Environment, 1, 4-13

Yunus R., and Yang J. (2012). Critical sustainability factors in Industrialised Building System. Construction Innovation, 12, 447-463

Yunus R., and Yang J. (2014) Improving ecological performance of Industrialized Building Systems in Malaysia. Construction Management and Economics, 32, 183-195 